\title{
On the Comovements Among Gold and Oil: A Multivariate Time-Varying Asymmetric Approach
}

\author{
Sirine Toumi \\ University of Tunis, Higher Institute of Management of Tunis
}

\begin{abstract}
Previous studies have reported that there is a relationship among gold and oil prices. This research analyses how gold and oil prices variables interact focusing on different Global financial crisis (GFC) phases, we adopt a multivariate asymmetric dynamic conditional correlation GARCH framework, during the period spanning from January $1^{\text {st }}, 2000$ until December $31^{\text {th }}$, 2017. Our empirical results suggest correlations' asymmetric responses among them. Moreover, the results indicate a correlations increase of gold and oil, during the crisis periods, suggesting different prices vulnerability.

JEL classification numbers: E3 D4
\end{abstract}

Keywords: DCC-FIAPARCH model, Global financial crisis, Volatility

DOI: $10.7176 / \mathrm{JETP} / 9-7-01$

Publication date:October $31^{\text {st }} 2019$

\section{Introduction}

Dynamic analysis of precious commodity such as gold and oil has received a lot of financial time series experts' attention, especially when research focuses on their prices multivariate analysis. Gold and oil multivariate analysis results will get so considerable interest of investors and financial analysts. Thus, investors will include gold because of its durability and its divisibility in their portfolio. In addition, they will prefer gold as a hedge or a "refuge" from the fluctuation of certain financial assets such as oil. Analysts growing interest is also due to the fact that oil prices increase or gold prices increase often pushes inflation rate on the rise, which therefore increases gold demand and as a result jacked up its prices on the market (Zhang and Wei, 2010). Oil prices have been considered as a major indicator in the global economy (Norden Amano, 1998). When oil prices rise, companies will suffer from profits losses. Such an increase may also lead to a decrease in disposable income and cause inflation that is impeding the steady economic growth (Wang, Lee and Nguyen, 2013). Nevertheless, imminent inflation will increase gold prices, because investors think that gold is a hedge against inflation. Narayan et al. (2010) improve on the cointegration approach and analyze the long-run relationship between gold and oil futures prices over the period 1963-2008 at different levels of maturity in order to gauge differences in hedging behavior. The results indicate that the gold and oil markets are cointegrated, which is presented as evidence of joint market inefficiency. The fact that annual data are employed for the analysis precludes the more detailed and comprehensive results that could be inferred from data of higher frequencies. Bampinas and Panagiotidis (2015) inspected the causal relationship among gold spot prices and crude oil prices before and after the latest financial crisis. In the pre-crisis period, causality was linear and unidirectional from oil to gold. In the post-crisis period, a bidirectional non-linear causality relationship emerged. Volatility spillovers come to light as the non-linearity source during this period. The causal linkages time path for both returns and levels (cointegration) assessed via dynamic bootstrap causality analysis. Their results found that the causal linkage from gold to oil is time dependent and that the non-Granger causality null hypothesis rejection rate increased considerably in the post-financial crisis period. The probability of gold Granger causing oil in the short-run, increased by further than $30 \%$ throughout the recent financial and euro crisis. Mo, He and Jiang (2017) examined the dynamic linkages among gold prices, US dollars and crude oil market and found that the dynamic gold-oil relationship is always positive. After early 2009 , US gold prices dropped suddenly and incoherent from world oil prices (Asche et al., 2012; Erdős, 2012; Øglend et al., 2015). Sephton and Mann (2018) examined how a shock to oil prices disturbs gold prices, with the impacts exposed to depend on mutually the shock size and the region within which the system lies when the shock had occurred.

These results allow us to conclude that if there is a relationship among oil and gold prices. Based on the analysis above, this paper aims to offer a novel perspective to explore the dynamic relationships between gold and oil prices to broaden the previous studies. Our study contributes to the literatures through investigating the longterm relationship by the time-varying DCCs that are captured from a multivariate student-t-FIAPARCH-DCC model which takes into account long memory behavior, speed of market information, asymmetries and leverage effects to examine the effect of the 2009 global financial crisis on the long-term interdependence.

\section{Econometric Methodology}

2.1 Univariate FIAPARCH (p, d, q) Model

The AR (1) process is one of the most common models for describing a time series $r_{t}$ of price returns. Its 
formulation is given as:

With

$$
(1-\xi L) r_{t}=c+\varepsilon_{t}, t \in \mathbb{N}
$$

$$
\varepsilon_{t}=\mathrm{Z}_{t} \sqrt{h_{t}}
$$

where $|\xi|<1,|c| \epsilon\left[0 \quad+\infty\left[\right.\right.$ and $\left\{Z_{t}\right\}$ are independently and identically distributed (i.i.d.) random variables with $\mathrm{E}\left(\mathrm{Z}_{t}\right)=0$. The variance $h_{t}$ is positive with probability equal to unity and is ameasurable function of $\Sigma_{t-1}$ which is the $\sigma$-algebra generated by $\left\{r_{t-1}, r_{t-1}, \ldots\right\}$. Therefore, $h_{t}$ denotes the conditional variance of the returns $\left\{r_{t}\right\}$, that is:

$$
\begin{gathered}
\mathrm{E}\left[r_{t} / \Sigma_{t-1}\right]=c+\xi r_{t-1} \\
\operatorname{Var}\left[r_{t} / \Sigma_{t-1}\right]=h_{t}
\end{gathered}
$$

Tse (1998) uses a FIAPARCH(1,d,1) model in order to examine the conditional heteroskedasticity. Its specification is given as:

$$
(1-\beta L)\left(h_{t}^{\delta / 2}-\omega\right)=\left[(1-\beta L)-(1-\phi L)(1-L)^{d}\right]\left(1+\gamma s_{t}\right)\left|\varepsilon_{T}\right|^{\delta}
$$

where $\omega \epsilon\left[0, \infty\left[,|\beta|<1,|\phi|<1,0 \leq d \leq 1, s_{t}=1\right.\right.$ if $\varepsilon_{t}<0$ and 0 otherwise, $(1-L)^{d}$ is

the financial differencing operator in terms of a hypergeometric function (Conrad et al. 2011), $\gamma$ is the leverage coefficient, and $\delta$ is the power term parameter (a Box-Cox transformation) that takes (finite) positive values.

A sufficient condition for the conditional variance $h_{t}$ to be positive almost surely for all t is that $\gamma>-1$ and the parameter combination $(\varphi, d, \beta)$ satisfies the inequality constraints provided in Conrad and Haag (2006) and Conrad (2010). When $\gamma>0$, negative shocks have more impact on volatility than positive shocks.

The advantage of this class of models is its flexibility since it includes a large number of alternative GARCH specifications. When $d=0$, the process in Eq. (5) reduces to the APARCH $(1,1)$ one of Ding et al. (1993), which nests two major classes of ARCH models. In particular, a Taylor/Schwert type of formulation (Taylor 1986; Schwert 1990) is specified when $\delta=1$ and a Bollerslev (1986) type is specified when $\delta=2$. When $\gamma=0$ and $\delta=$ 2 , the process in Eq. (5) reduces to the FIGARCH $(1$, d, 1) specification (Baillie et al. 1996; Bollerslev and Mikkelsen 1996) which includes Bollerslev's (1986) GARCH model (when $d=0$ ) and the IGARCH specification (when $d=1$ ) as special cases.

\subsection{Bivariate FIAPARCH model with dynamic conditional correlations}

In what follow, we introduce the multivariate FIAPARCH process (M-FIAPARCH) taking into account the dynamic conditional correlation (DCC) hypothesis (see Dimitriou et al., 2013) advanced by Engle (2002). This approach generalizes the Multivariate Constant Conditional Correlation (CCC) FIAPARCH model of Conrad et al. (2011). The multivariate DCC model of Engle (2002), Tse, and Tsui (2002) involves two stages to estimate the conditional covariance matrix $H_{t}$.

In the first stage, we fit a univariate FIAPARCH $(1, \mathrm{~d}, 1)$ model in order to obtain the estimations of $\sqrt{h_{i i t}}$ The daily data are assumed to be generated by a multivariate $\operatorname{AR}(1)$ process of the following form:

$$
Z(L) r_{t}=\mu_{0}+\varepsilon_{t}
$$

$\mu_{0}=\left[\mu_{0, i}\right]_{i=1, \ldots n}$ : the $N$-dimensional column vector of constants;

$\left|\mu_{0, i}\right| \in[0, \infty[$;

$Z(L)=\operatorname{diag}\{\psi(L)\}:$ an $N \times N$ diagonal matrix ;

$\psi(L)=\left[1-\psi_{i} L\right]_{i=1, \ldots, n}$;

$\left|\psi_{i}\right|<1$

$r_{t}=\left[r_{i, t}\right]_{i=1, \ldots N}:$ the $N$-dimensional column vector of returns;

$\varepsilon_{t}=\left[\varepsilon_{i, t}\right]_{i=1, \ldots N}: \quad$ the $N$-dimensional column vector of residuals.

The residual vector is given by:

$$
\varepsilon_{t}=z_{t} \odot h_{t}^{\wedge 1 / 2}
$$

$\odot:$ the Hadamard product; $\Lambda$ : the elementwise exponentiation.

$h_{t}=\left[h_{i, t}\right]_{i=1, \ldots N}$ is $\Sigma_{t-1}$ measurable and the stochastic vector $z_{t}=\left[z_{i, t}\right]_{i=1, \ldots N}$ is independent and identically distributedwith mean zero and positive definite covariance matrix

$\rho=\left[\rho_{i j t}\right]_{i, j=1, \ldots N}$ with $\rho_{i j}=1$ for $=j$. Note that $E\left(\varepsilon_{t} / \mathcal{F}_{t-1}\right)=0$ and

$H_{t}=\left(\varepsilon_{t} \varepsilon_{t}^{\prime} / \mathcal{F}_{t-1}\right)=\operatorname{diag}\left(h_{t}^{\wedge 1 / 2}\right) \rho \operatorname{diag}\left(h_{t}^{\Lambda^{1 / 2}}\right)$ is the vector of conditional variances and

$\rho_{i, j, t}=h_{i, j, t} / \sqrt{h_{i, j, t} h_{i, j, t}} \forall i, j=1, \ldots, N$ are the dynamic conditional correlations.

The multivariate FIAPARCH $(1, \mathrm{~d}, 1)$ is given by: 


$$
B(L)\left(h_{t}^{\wedge \delta / 2}-\omega\right)=[B(L)-\Delta(L) \Phi(L)]\left[I_{N}+\Gamma_{t}\right]\left|\varepsilon_{t}\right|^{\wedge \delta}
$$

where $\left|\varepsilon_{t}\right|$ is the vector $\varepsilon_{t}$ with elements stripped of negative values.

Besides, $B(L)=\operatorname{diag}\{\beta(L)\}$ with $\beta(L)=\left[1-\beta_{i}\right]_{i=1, . ., N}$ and $\left|\beta_{i}\right|<1$.

Moreover, $\Phi(L)=\operatorname{diag}\{\phi(L)\}$ with $\phi(L)=\left[1-\phi_{i}\right]_{i=1, \ldots, N}$ and $\left|\phi_{i}\right|<1$.

In addition, $\omega=\left[1-\omega_{i}\right]_{i=1, \ldots, N}$ with $\omega_{i} \in\left[0, \infty\left[\right.\right.$ et $\Delta(L)=\operatorname{diag}\{d(L)\}$ with $d(L)=\left[(1-L)^{d_{i}}\right]_{i=1, \ldots, N} \forall 0 \leq$ $d_{i} \leq 1$. Finally, $\Gamma_{t}=\operatorname{diag}\left\{\gamma \odot s_{t}\right\}$ withe $\gamma=\left[1-\gamma_{i}\right]_{i=1, \ldots, N}$ and $s_{t}=\left[s_{i t}\right]_{i=1, . ., N}$ where $s_{i t}=1$ if $\varepsilon_{i t}<0$ and 0 otherwise.

In the second stage, we estimate the conditional correlation using the transformed stock return residuals, which are estimated by their standard deviations from the first stage. The multivariate conditional variance is specified as follows:

$$
H_{t}=D_{t} R_{t} D_{t}
$$

Where $D_{t}=\operatorname{diag}\left(h_{11 t}^{1 / 2}, \ldots, h_{N N t}^{1 / 2}\right)$ denotes the conditional variance derived from the univariate $\operatorname{AR}(1)$ FIAPARCH $(1, \mathrm{~d}, 1)$ model and $R_{t}=\left(1-\theta_{1}-\theta_{2}\right) R+\theta_{1} \psi_{t-1}+\theta_{2} R_{t-1}$ is the conditional correlation matrix ${ }^{1}$. Engle (2002) derives a different form of DCC model. The evolution of the correlation in

DCC is given by: $\quad Q_{t}=(1-\alpha-\beta) \bar{Q}+\alpha z_{t-1}+\beta Q_{t-1}$

In addition, $\theta_{1}$ and $\theta_{2}$ are the non-negative parameters satisfying $\left(\theta_{1}+\theta_{2}\right)<1$ and $\mathrm{R}=\left\{\rho_{i j}\right\}$ is a time-invariant symmetric $N \times N$ positive definite parameter matrix with $\rho_{i j}=1$ and $\psi_{t-1}$

is the $N \times N$ correlation matrix of $\varepsilon_{\tau}$ for $\tau=t-M, t-M+1, \ldots, t-1$. The $i, j-t h$ element of the matrix $\psi_{t-1}$ is given as follows:

$$
\psi_{i j, t-1}=\frac{\sum_{m=1}^{M} z_{i, t-m^{z} j, t-m}}{\sqrt{\left(\sum_{m=1}^{M} z_{i, t-m}^{2}\right)\left(\sum_{m=1}^{M} z_{j, t-m}^{2}\right)}}, \quad 1 \leq i \leq j \leq N
$$

Where $z_{i t}=\varepsilon_{i t} / \sqrt{h_{i i t}}$ is the transformed stock return residuals by their estimated standard deviations taken from the univariate AR(1)-FIAPARCH( $1, \mathrm{~d}, 1)$ model.

The matrix $\psi_{t-1}$ could be expressed as follows:

$$
\psi_{t-1}=B_{t-1}^{-1} L_{t-1} L_{t-1}^{\prime} B_{t-1}^{-1}
$$

Where $B_{t-1}$ is a $N \times N$ diagonal matrix with $i-t h$ diagonal element given by $\left(\sum_{m=1}^{M} z_{i, t-m}^{2}\right)$ and $L_{t-1}=$ $\left(z_{t-1}, \ldots, z_{t-M}\right)$ is a $N \times N$ matrix, $z_{t}=\left(z_{1 t}, \ldots, z_{N t}\right)^{\prime}$.

To ensure the positivity of $\psi_{t-1}$ and therefore of $R_{t}$ a necessary condition is that $M \leq N$. Then $R_{t}$ itself is a correlation matrix if $R_{t-1}$ is also a correlation matrix. The correlation coefficient in a bivariate case is given as:

$$
\rho_{12, t}=\left(1-\theta_{1} \theta_{2}\right) \rho_{12}+\theta_{2} \rho_{12, t}+\theta_{1} \frac{\sum_{m=1}^{M} z_{1, t-m^{z}, t-m}}{\sqrt{\left(\sum_{m=1}^{M} z_{1, t-m}^{2}\right)\left(\sum_{m=1}^{M} z_{2, t-m}^{2}\right)}}
$$

\section{Data and preliminary analyses}

The data comprises daily gold prices and oil (wti) prices. All the data are taken from DataStream. The study period spans from 01/01/2000 until 31/12/2017, leading to a sample size of 8274 observations. For each gold and oil prices, the continuously compounded return is calculated as $R_{t}=100 * \ln \left(\frac{P_{t}}{P_{t-1}}\right)$, where $P_{t}$ is the price on day $t$ and $P_{t-1}$ is the price on day $t-1$.

Summary statistics of gold and oil prices are displayed in Table 1. From this table, gold and oil prices are volatile, as measured by the standard deviation of $2.0556 \%$ and $2.7614 \%$, Besides, we note that gold and oil prices have the highest level of kurtosis, indicating that extreme changes tend to occur more frequently for gold and oil markets.

As well, gold and oil prices exhibit high values of excess kurtosis. To accommodate the existence of "fat tails", we assume T-Student distributed innovations. Furthermore, the Jarque-Bera statistic rejects normality at the $1 \%$ level for all gold and oil prices.

\footnotetext{
${ }^{1} Q=\left(q_{i j t}\right) N \times \mathrm{N}$ time-varying covariance matrix of $z_{t}, \bar{Q}=E\left[z_{t} z_{t}{ }^{\prime}\right]$ denotes the $n \times n$ unconditional variance matrix of $z_{t}$, while $\alpha$ and $\beta$ are nonnegative parameters satisfying $(\alpha+\beta)<1$. Since $Q_{t}$ ne possède généralement pas d'unités sur la diagonale, la matrice de corrélation conditionnelle $R_{t}$ is derived by scaling $Q_{t}$ as follows: $R_{t}=\left(\operatorname{diag}\left(Q_{t}\right)\right)^{-1 / 2}\left(\operatorname{diag}\left(Q_{t}\right)\right)^{-1 / 2}$
} 
Table 1 : Descriptive statistics

\begin{tabular}{|c|c|c|c|c|c|c|c|}
\hline & Mean & Maximum & Minimum & Std.Deviation & Skewness & Excess Kurtosis & Jarque-Bera \\
\hline GOLD & -0.0228 & 9.8206 & -8.6251 & 2.05564 & $-0.483 * * *$ & $4.37 * * *$ & $13310.83 * * *$ \\
\hline WTI & 0.0101 & 16.4141 & -17.0923 & 2.7614 & $-0.482 * * *$ & $7.882 * * *$ & $27661.81 * * *$ \\
\hline
\end{tabular}

Notes: The superscripts $* * *, * *$ and $*$ denote the statistical significance at $1 \%, 5 \%$ and $10 \%$ levels, respectively.

In Table 2 which displays the results of Serial correlation and LM-ARCH Test, the Ljung-Box test for correlating series rejects the null hypothesis of autocorrelations at $1 \%, 5 \%$ and $10 \%$ levels, respectively.

Table 2 : Serial correlation and LM-ARCH Test

\begin{tabular}{|c|c|c|c|}
\hline \multirow{2}{*}{} & \multicolumn{2}{|c|}{ Serial Correlation } & LM-ARCH \\
\cline { 2 - 4 } & $\operatorname{LB}(20)$ & $\operatorname{LB}^{2}(20)$ & ARCH(10) \\
\hline GOLD & $108.3413 * * *$ & $2048.4024 * * *$ & $88.9581 * * *$ \\
\hline WTI & $283.1034 * * *$ & $4501.3217 * * *$ & $91.2396 * * *$ \\
\hline
\end{tabular}

Notes: The superscripts ***,** and * denote the statistical significance at $1 \%, 5 \%$ and $10 \%$ levels, respectively.

Engle and $\mathrm{Ng}$ (1993) propose a set of volatility asymmetry tests, known as the sign and size of bias tests. Engle and $\mathrm{Ng}$ tests should be used to decide if an asymmetrical model is necessary for a given series or if the symmetrical GARCH model can be judged adequate. In practice, Engle and $\mathrm{Ng}$ tests are generally applied to the residue of a GARCH adjustment to the return data.

Defining $S_{t-1}^{-}$as variable indicators model as:

$$
S_{t-1}^{-}=\left\{\begin{array}{cc}
1 & \hat{z}_{t-1}<0 \\
0 & \text { Otherwise }
\end{array}\right\}
$$

The test of bias sign is based on the importance or not $\emptyset_{1}$ in the following regression:

$$
\hat{z}_{t}^{2}=\emptyset_{0}+\emptyset_{1} S_{t-1}^{-}+v_{t}
$$

Where $v_{t}$ is an independent and identically distributed error term. If positive and negative shocks on $\hat{z}_{t-1}$. The impact of conditional variance is different, so $\emptyset_{1}$ will be statistically significant.

It could also be the case that the greatness or the size of the shock will affect whether or not the volatility answer to shocks is symmetrical. In this case, a test of negative size bias would be made, based on a regression where $S_{t-1}^{-}$is used as a binary variable.

Negative size bias is argued to be present if $\emptyset_{1}$ is statistically significant in the following regression:

$$
\hat{z}_{t}^{2}=\emptyset_{0}+\emptyset_{1} S_{t-1}^{-} Z_{t-1}+v_{t}
$$

Finally, we define $S_{t-1}^{+}=1-S_{t-1}^{-}$, so that $S_{t-1}^{+}$selects its comments with positive innovations. Engle and Ng (1993) propose a test for partiality cause of bias signs and size based on the following regression:

$$
\hat{z}_{t}^{2}=\emptyset_{0}+\emptyset_{1} S_{t-1}^{-}+\emptyset_{2} S_{t-1}^{-} Z_{t-1}+\emptyset_{3} S_{t-1}^{+} Z_{t-1}+v_{t}
$$

$\emptyset_{1}$ significance indicates the existence of signs bias, where positive and negative shocks have different effects on the future volatility, compared to the symmetrical response required by the standard formulation of GARCH. However, the meaning of $\emptyset_{2}$ or of $\emptyset_{3}$ suggests the existence of size bias, where not only the sign, but the magnitude of the shock is important. A common test statistic is formulated in standard mode by calculating $T R^{2}$ regression, which will be asymptotically follow a $\chi^{2}$ distribution with 3 freedom degrees under the null assumption of no asymmetric effect.

Table 3 : Tests for Sign and Size Bias

\begin{tabular}{|c|c|c|}
\hline Variables & GOLD & WTI \\
\hline \multirow{2}{*}{$\emptyset_{0}$} & $1.0273^{* * *}$ & $1.0751^{* * *}$ \\
& $(0.0000)$ & $0.0000)$ \\
\hline \multirow{2}{*}{$\emptyset_{1}$} & $-0.4305^{* * *}$ & 0.0981 \\
& $(0.0004)$ & $0.7734)$ \\
\hline \multirow{2}{*}{$\emptyset_{2}$} & $0.1053^{* *}$ & $(0.0628$ \\
\multirow{2}{*}{$\emptyset_{3}$} & $(0.0443)$ & $-0.4031 * * *$ \\
& $-0.196 * * *$ & $(0.0002)$ \\
\hline \multirow{2}{*}{$\chi^{2}(3)$} & $(0.0008)$ & $21.7551 * * *$ \\
\end{tabular}

Notes: The superscripts $* * * * *$ and $*$ denote the statistical significance at $1 \%, 5 \%$ and $10 \%$ levels, respectively.

The results in Table 3 show that symmetric GARCH model residues for oil price do not suffer from sign biases and have negative size biases. But they display a positive size bias. These results also show that symmetric GARCH model residuals for gold price variable exhibit sign bias, negative size bias and positive size bias. The joint effect $\chi^{2}(3)$ at significant values of $1 \%$ for all these variables, which demonstrates a rejection of the null 
hypothesis of non-asymmetries. The overall results would therefore suggest a motivation for estimating an asymmetric volatility model for these variables.

Table 4 : Long Memory tests

\begin{tabular}{|c|c|c|c|c|}
\hline \multirow{2}{*}{$\begin{array}{c}\text { GPH test-d } \\
\text { Estimates }\end{array}$} & \multicolumn{2}{|c|}{ Squared returns } & \multicolumn{2}{c|}{ Absolute returns } \\
\cline { 2 - 5 } & $\mathrm{m}=\mathrm{T}^{0.5}$ & $\mathrm{~m}=\mathrm{T}^{0.6}$ & $\mathrm{~m}=\mathrm{T}^{0.5}$ & $\mathrm{~m}=\mathrm{T}^{0.6}$ \\
\hline GOLD & $101.3418^{* * *}$ & $3248.1128^{* * *}$ & $0.2965^{*}$ & $0.4513^{*}$ \\
\hline WTI & $201.9279 * * *$ & $3021.4019 * * *$ & $0.2397^{*}$ & $0.4589 *$ \\
\hline
\end{tabular}

Notes: The superscripts ***,** and * denote the statistical significance at $1 \%, 5 \%$ and $10 \%$ levels, respectively.

Long memory tests results are displayed in Table 4. Based on these results, we reject the null hypothesis of no long memory for absolute and squared returns at $1 \%$ significance level. Subsequently, all volatilities proxies seem to be governed by a fractionally integrated process. Thus, FIAPARCH seem to be an appropriate specification to capture volatility clustering, long-range memory characteristics and asymmetry.

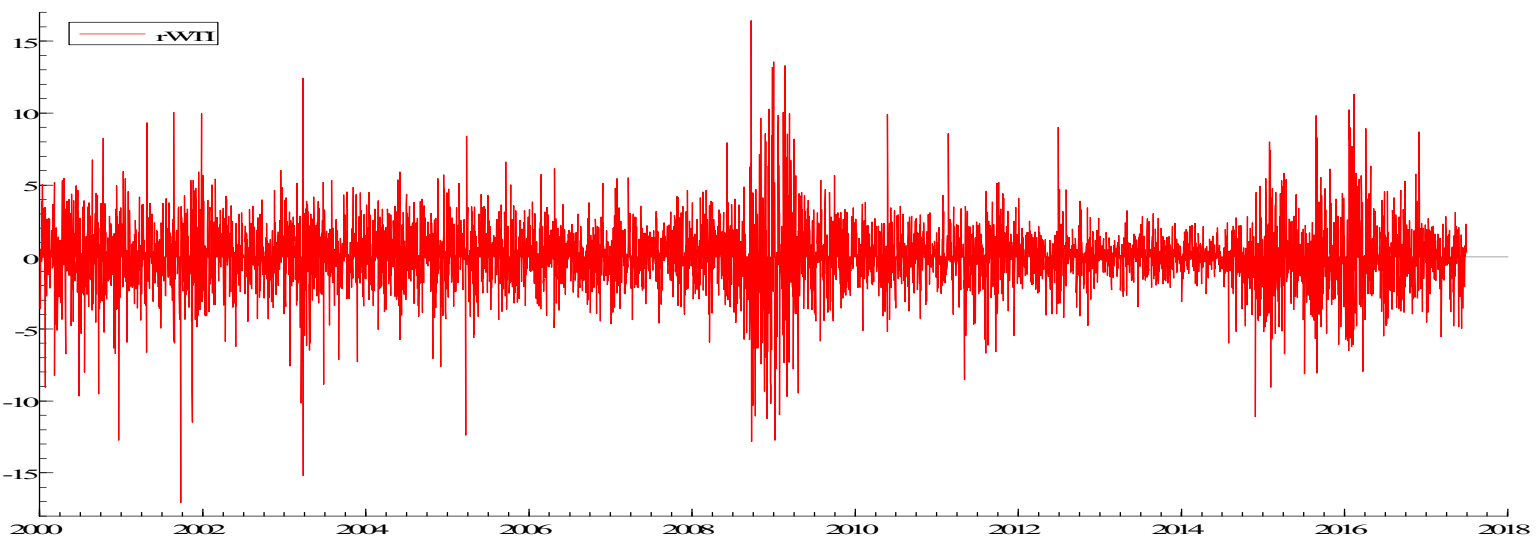

Figure 1. Oil (WTI) behavior over time

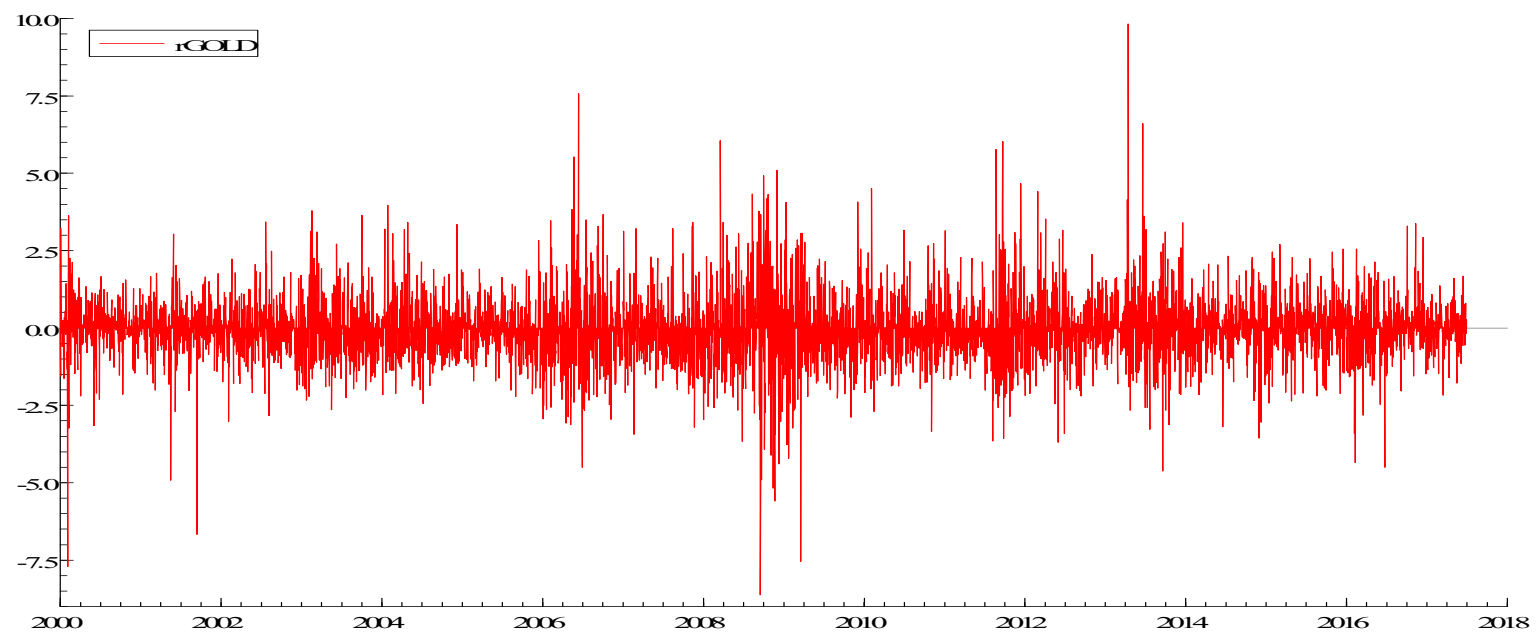

Figure 2. Gold behavior over time

Figures 1 and 2. above, plots the evolution of gold and oil prices behavior over time and thus during the period from 01/01/2000 until 31/12/2017. The figures show significant variations in the levels during the turmoil, especially at the time of Lehman Brothers failure (September 15, 2008). Specifically, when the global financial crisis triggered, there was a decline for all prices.

\section{Crisis Periods Specification}

Recent crises have some unique characteristics, such as length, reach and origins of crisis. Many studies use key economic and financial events to define crisis duration and beginnings (Forbes and Rigobon, 2002; Chiang et al., 2007). Nevertheless, other studies follow a statistical approach using the Markov regime change processes to identify endogenously the crisis period (Boyer et al., 2006; Rodriguez, 2007). We should note that economic and statistical approaches are at least partly arbitrary. Some studies help to avoid discretion in defining the crisis period by using discretion in choosing the econometric model to estimate the position of the crisis period over time. Baur 
(2012) used key financial and economic events, he estimated excessive volatility to identify the crisis period, and he studied the transmission of the global financial crisis from the financial sector to the real economy.

In this study, we specify the duration of global financial crisis and their phases according to economic and statistical approaches. We follow a statistical approach based on a Markov-dynamic regression model (MS-DR), which takes into account the endogenous structural breaks and thus allows us defining the beginning and the end of each crises phase.

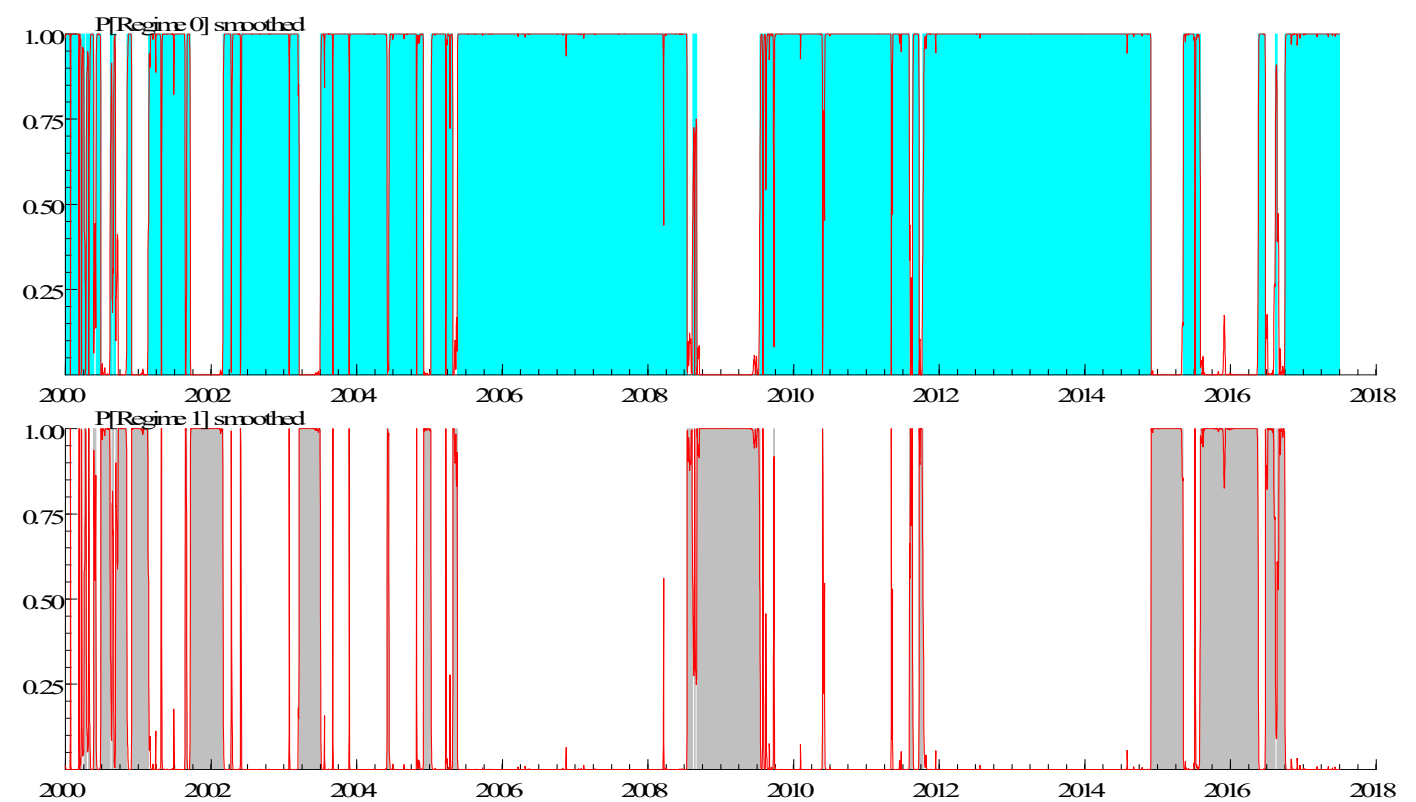

Figure 3. Regime classification of Oil conditional volatilities

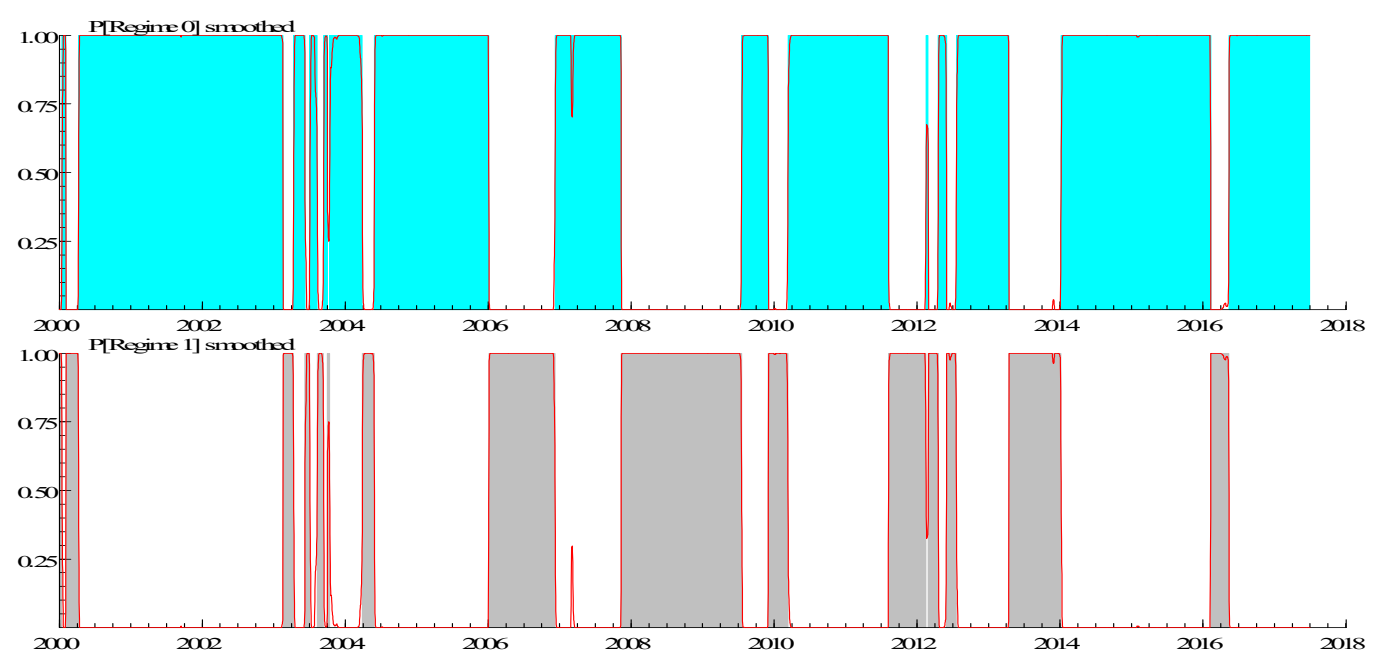

Figure 4. Regime classification of Gold conditional volatilities

Figures 3 and 4 above, show regime classification of oil and gold conditional volatilities. Regime 0 , in light blue, that matches up to periods of stable and low volatility. Regime 1, in grey, denotes periods of rising and persistent volatility returns. The red columns indicate the smoothed regime probabilities, while the grey shaded spaces are the regimes of excess volatilities according to MS-DR model. 


\section{Estimation results}

Table 5. Univariate FIAPARCH $(1, \mathrm{~d}, 1)$ Model

\begin{tabular}{|c|l|c|c|c|}
\hline & \multicolumn{2}{|c|}{ GOLD } & \multicolumn{2}{c|}{ OIL } \\
\hline ESTIMATION & Coeff & t-prob & Coeff & t-prob \\
\hline CST(M) & 0.0019 & 0.0000 & -0.0046 & 0.4312 \\
\hline AR(1) & 0.0044 & 0.0000 & 0.0042 & 0.7918 \\
\hline CST(V) & 0.0151 & 0.4689 & 0.0014 & 0.2601 \\
\hline $\mathbf{d}$ & 0.5531 & 0.0000 & 0.8605 & 0.0000 \\
\hline ARCH(Phi1) & 0.2912 & 0.0000 & 0.1710 & 0.0003 \\
\hline GARCH(Beta1) & 0.7406 & 0.0000 & 0.9579 & 0.0000 \\
\hline APARCH(Gamma1) & -0.3840 & 0.0000 & -0.0583 & 0.4635 \\
\hline APARCH(Delta) & 1.6827 & 0.0000 & 1.7862 & 0.0000 \\
\hline (df) & $8.8146^{* * *}$ & 0.0000 & $6.1827 * * *$ & 0.0000 \\
\hline
\end{tabular}

In table 5 the ARCH and GARCH parameters (Phil and Beta1) are statistically significant and non-negative for all the returns of the oil and gold which justifies the relevance of the specification FIAPARCH $(1, d, 1)$. The tstudent degree of freedom parameter (df) is very significant for all returns. This result confirms our preliminary analysis and, subsequently, the choice of t-student as an appropriate distribution. In addition the term $(\gamma)$ leverage estimates are statistically significant, indicating an asymmetric response of volatilities to positive and negative shocks. Estimates of the power term $(\delta)$ are very significant for prices.

Conrad, Karanasos and Zeng (2011) show that when the series is very likely to follow a non-normal error distribution, the superiority of a squared term $(\delta=2)$ is lost and other power transformations can be more appropriate. In addition, all currencies display a significant fractional $(d)$ parameter, which indicates a high degree of persistence behavior. This implies that the impact of negative shocks and their persistence on the conditional volatility of oil and gold returns. Table 6 reports the estimation results of the bivariate FIAPARCH (1, d, 1)-DCC model. The ARCH and GARCH parameters of the DCC $(1,1)$ model capture, respectively, the effects of standardized lagged shocks and the lagged dynamic conditional correlations effects on current dynamic conditional correlation. They are statistically significant. Moreover, they are non-negative, justifying the appropriateness of the FIAPARCH model.

Table 6 : DCC- FIAPARCH $(1$, d, 1) Model Estimation Results

\begin{tabular}{|c|c|c|}
\hline \multicolumn{3}{|c|}{ Panel A } \\
\hline \multicolumn{3}{|c|}{ GOLD /WTI } \\
\hline Rho & 0.0413 & 0.3632 \\
\hline Alpha & 0.0021 & 0.0764 \\
\hline Beta & 0.6817 & 0.0000 \\
\hline$v$ & 8.6185 & 0.0000 \\
\hline \multicolumn{3}{|c|}{ Panel B } \\
\hline Hosking(20) & 342.089 & 1.0000 \\
\hline Hosking $^{2}(20)$ & 530.901 & 0.0000 \\
\hline Li - McLeod(20) $_{\text {McLood }}^{2}(20)$ & 341.051 & 0.0000 \\
\hline Li $_{\text {McLeod }}$ & 729.343 & 1.0000 \\
\hline
\end{tabular}

As shown in Table 6, the estimated coefficients are significantly positive for the pair of GOLD /WTI. Besides, the t-student freedom degrees parameters are highly significant, supporting the choice of this distribution. The statistical significance of the DCC parameters reveals a considerable time-varying co-movement and thus a high persistence of the conditional correlation. This implies that the volatility displays a highly persistent manner.

The multivariate FIAPARCH-DCC model is so important to consider in our analysis since it has some key advantages. First, it captures the long range dependence property. Second, it allows obtaining all possible pairwise conditional correlation coefficients for GOLD /WT in the sample. Third, it is possible to investigate their behavior during periods of particular interest, such as the global financial crises period. Finally, it is crucial to check whether the selected GOLD /WTI display evidence of bivariate long memory ARCH effects and to test ability of the bivariate FIAPARCH specification to capture the volatility linkages between gold and oil. In our study, we refer to the most broadly used diagnostic tests, namely the Hosking's and Li and McLeod's Multivariate Portmanteau statistics on both standardized and squared standardized residuals. According to Hosking (1980), Li and McLeod (1981) and McLeod and Li (1983) autocorrelation test results reported in Table 5 (Panel B), the multivariate 
diagnostic tests allow accepting the null hypothesis of no serial correlation on both standardized and squared standardized residuals and thus there is no evidence of statistical misspecification.

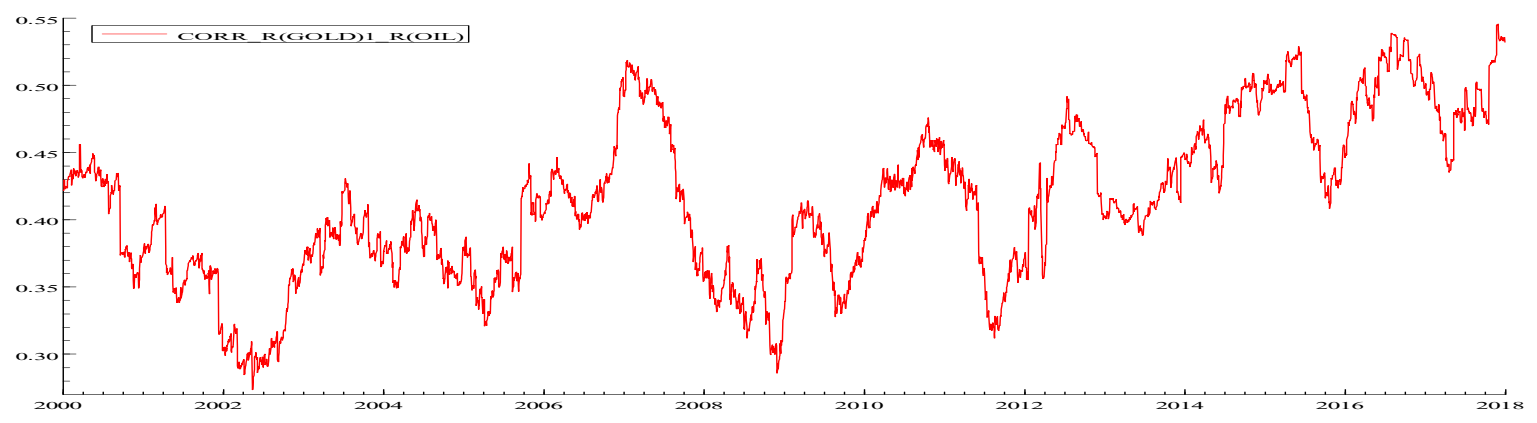

Figure 5. DCC behavior over time (WTI/GOLD)

Figure 5 above, illustrate the evolution of the estimated dynamic conditional correlations dynamics among gold and oil. Compared to the pre-crisis period, the estimated DCC show a decline during the post-crisis period. Such evidence is in contrast with the findings of previous research on GOLD /WTI. which show increases in correlations during periods of financial turmoil (Kenourgios and Padhi, 2012; Dimitriou et al., 2013; Dimitriou and Kenourgios, 2013). Nevertheless, the different path of the estimated DCC displays fluctuations for GOLD /WTI during the global financial crises phases, suggesting that the assumption of constant correlation is not appropriate. The above findings motivate a more extensive analysis of DCC, in order to capture contagion dynamics during different phases of the two crises.

\section{The DCC behavior during crisis periods}

We next provide further results on the contagion effects during the crises. Using various dummy variables allows us to identify which of the sub-periods exhibit contagion effects of gold and oil price. We create dummies, which are equal to unity for the corresponding crisis phase and zero otherwise, to the following mean equation in order to describe the behavior of DCCs over time:

$$
\rho_{i j, t}=c_{0}+\sum_{p=1}^{P} \psi_{p} \rho_{i j, t-p}+\sum_{k=1}^{\lambda} \beta_{k} d u m m y_{k, t} \eta_{i j, t}
$$

where $c_{0}$ is a constant term, $\rho_{i j, t}$ is the pairwise conditional correlation

$\mathrm{k}=1 \ldots \lambda$ is the number of dummy variables corresponding to crises, which are identified based on an economic and a statistical approach. Furthermore, the conditional variance equation is assumed to follow an asymmetric GARCH(1,1) specification of Glosten, Jagannathan and Runkle (1993) including the dummy variables identified by the two approaches :

$h_{i j, t}=\alpha_{0}+\alpha_{1} h_{i j, t-1}+\sum_{k=1}^{\lambda} \zeta_{k} d u m m y_{k, t}+v_{1} \eta_{i j, t-1}^{2}+\alpha_{2} \eta_{i j, t-1}^{2} I\left(\eta_{i j, t-1}<0\right)$

As the model implies, estimated dummy coefficients significance indicates structural changes in mean or/and variance shifts of the correlation coefficients due to external shocks during the crises. According to Dimitriou and Kenourgios (2013), a positive and statistically significant dummy coefficient in the mean equation indicates that the correlation during a specific phase of the crisis is significantly different from that in the previous phase, supporting the existence of spillover effects among gold and oil prices. Furthermore, a positive and statistically significant dummy coefficient in the variance equation indicates a higher volatility of the correlation coefficients. This suggests that the stability of the correlation is less reliable, causing some doubts on using the estimated correlation coefficient as a guide for portfolio decisions. 
Table 7. Tests of changes in dynamic correlations during the crisis

\begin{tabular}{|c|c|c|}
\hline & \multicolumn{2}{|c|}{$\boldsymbol{\rho}_{\text {GOLD } / W T I}$} \\
\hline Mean Eq & Coeff & Signif \\
\hline$c_{0}$ & 0.0088 & 0.0001 \\
\hline$\psi_{1}$ & 0.9131 & 0.0000 \\
\hline$\beta_{1}$ & 0.0036 & 0.0517 \\
\hline$\beta_{2}$ & 0.0071 & 0.9113 \\
\hline$\beta_{3}$ & 0.0065 & 0.0356 \\
\hline Variance Eq. & - & - \\
\hline$\alpha_{0}$ & 0.0003 & 0.0000 \\
\hline$\alpha_{1}$ & 0.1019 & 0.0000 \\
\hline$\nu_{1}$ & 0.4861 & 0.0000 \\
\hline$\alpha_{2}$ & 0.0058 & 0.0000 \\
\hline$\zeta_{1}$ & 0.0729 & 0.0000 \\
\hline$\zeta_{2}$ & 0.0681 & 0.0013 \\
\hline$\zeta_{3}$ & 0.0863 & 0.0001 \\
\hline$\zeta_{4}$ & 0.0613 & 0.0000 \\
\hline Diagnostics & - & - \\
\hline LB $(20)$ & 22.4577 & 0.2681 \\
\hline $\mathrm{LB}^{2}(20)$ & 10.6071 & 0.8665 \\
\hline
\end{tabular}

Table 7 shows the estimations of the mean and variance equations, setting a dummy variable for each crisis phase according to the economic approach. The constant terms $c_{0}$ and the autoregressive term $\left(\psi_{1}\right)$ are both statistically significant for all DCCs, with the latter taking values close to unity, indicating a strong persistence in the conditional correlations among the examined prices. For the mean equation, dummy coefficient $\beta_{1}$ for the global financial crisis phase 1 is positive and significantly. This evidence suggests that the DCCs between gold and oil have amplified during phase 1, supporting the existence of a difference in prices vulnerability. At the global financial crisis phase 2 , the dummy coefficient $\beta_{2}$ is positive and not statistically significant for the GOLD /WTI prices, supporting a decrease in DCCs.

This suggests that the relationship between gold and oil prices actually decreased during this phase. We could define this finding as a "currency contagion effect". During the global financial crisis phase 3 , positive and statistically significant dummy coefficient $\beta_{3}$ exists for only the prices pairs, implying an increase of DCCs. Finally, the variance estimations have been reported in Table 7 . The dummy coefficients $\zeta_{k, t}$ where $\mathrm{k}=1,2,3,4$ for gold and oil are positive and statistically significant across several crisis phases. This finding means that the volatility of correlation coefficients is increased, implying that the correlations stability is less reliable for investment strategies implementation.

\section{Conclusion}

Whereas time fluctuating correlations of gold and oil prices have seen large research, reasonably little attention has given to correlations dynamics within a market. This research analyses how gold and oil prices variables interact with each other. In this paper, we evaluate the dynamic conditional correlation between the within gold and oil markets by means of the Dynamic Conditional Correlation (DCC-FIAPARCH) model. We used this model to examine and analyze contagion risk between them. Our empirical results point out that gold and oil prices exhibit asymmetry in the conditional variances. For that reason, the results point to the importance of applying a suitably flexible modeling framework to truthfully estimate the interaction between them.

The conditional correlation surrounded by pairs gold and oil displays higher dependency when it was driven by negative expansions to variations than it is by positive improvements. In addition, market correlations turn out to be more volatile throughout the global financial crisis. The time-varying correlation coefficients empirical analysis, during the main crisis periods, provides contagion approval evidence. Our empirical results seem to be essential to researchers and practitioners and mainly to active investors and portfolio managers who include gold and oil in their equities portfolios. Actually, the high correlation coefficients, during crises periods, involve that the international diversification advantage, by holding an involving diverse portfolio from the contagious markets, drop.

The findings lead to essential implications for investors' and policy makers' perception. They have a great consequence on international investors' financial choices on managing their risk disclosures to gold and oil and on winning advantages of potential diversification opportunities that may arise due to released dependence amongst the market. Markets linkages' growth correlation throughout crisis periods shows the different prices vulnerability and implies a portfolio diversification benefits decline, meanwhile holding a diversified portfolio with gold and oil will be less subject to systematic risk. As pointed out by Sephton and Mann (2018), it is very 
important to appreciate those variables simultaneity therefore portfolio managers, investors and policy makers can make better decisions. Additionally, correlations' behaviors considered as confirmation of non-cooperative monetary policies nearby the world and highlight the need for some form of policy organization among central banks. As a final point, dynamic linkages' different patterns between gold and oil prices might influence the intercontinental trade flows and the multinational corporations' accomplishments, as they generate ambiguity with concern to exports and imports.

ACKNOWLEDGEMENTS: The author is grateful to an anonymous referee and the editor for many helpful comments and suggestions. Any errors or omissions are, however, our own.

\section{References}

[1] R. A. Amano., S. V. Norden, Oil prices and the rise and fall of the US real exchange rate, J. Int. Money Finance, 17 (2), (1998), 299-316.

[2] Asche, F., Øglend, A., Osmundsen, P., Gas versus oil prices the impact of shale gas, Energy Policy, 47, (2012), 117-124.

[3] Bampinas, G., Panagiotidis, T., On the relationship between oil and gold before and after financial crisis: linear, nonlinear and time-varying causality testing, Stud. Nonlinear Dyn. Econ, 19 (5), (2015), 657-668.

[4] Baur, G., (2012)Financial contagion and the real economy, Journal of Banking and Finance, (2012), 26802698.

[5] Boyer, B., Kumagai, T., and Yuan, K., How do crises spread? Evidence from accessible and inaccessible stock indices, Journal of Finance, 61, (2006), 957-1003.

[6] Brown, S., Yücel, M., Deliverability and regional pricing in U.S. natural gas markets; Energy Economics, 30 , (2008), 2441-2453.

[7] Chiang, T.C., Jeon, B.N., and Li, H., Dynamic Correlation Analysis of Financial Contagion: Evidence from Asian Markets, Journal of International Money and Finance, 26, (2007), 1206-1228.

[8] Conrad, C., Karanasos, M., and Zeng, N. (2011),Multivariate fractionally integrated APARCH modeling of stock market volatility : A multi-country study, Journal of Empirical Finance, 18, (2011), 147-159.

[9] Dimitriou, D., Kenourgios, D., and Simos, T., Global financial crisis and emerging stock market contagion: a multivariate FIAPARCH-DCC approach, International Review of Financial Analysis, 30, (2013), 46-56.

[10] Dimitriou, D., and Kenourgios, D., Financial crises and dynamic linkages among international currencies, Journal of International Financial Markets, Institutions and Money, 26, (2013), 319-332.

[11] Engle, R., Dynamic conditional correlation: a simple class of multivariate generalized autoregressive conditional heteroskedasticity models, Journal of Business and Economic Statistics, 20(3), (2002), 339-350.

[12] Engle, F., and $\mathrm{Ng}, \mathrm{K}$., Measuring and testing the impact of news on volatility, Journal of Finance, 48, (1993), $1749-1778$

[13] Erdős, P., Have oil and gas prices got separated? . Energy Policy, 49, (2012), 707-718.

[14] Forbes, K., Rigobon, R., No contagion, only interdependence: Measuring stock market co-movements, Journal of Finance, 57(5), (2002), 2223-2261.

[15] Glosten, R., Jagannathan, R., Runkle, E., On The relation between the expected value and the volatility of nominal excess return on stocks, Journal of Finance, 48, (1993), 1779-1801.

[16] Hosking, J.R.M.,The multivariate portmanteau statistic, Journal of American Statistical Association, 75, (1980), 602-608.

[17] Kenourgios, D., and Padhi, P., Emerging markets and financial crises : Regional, global or isolated shocks?, Journal of Multinational Financial Management, 22, (2012), 24-38.

[18] Li, K., McLeod, I., Distribution of the residual autocorrelations in multivariate ARMA time series models, Journal of the Royal Statistical Society, series B (Methodological), 43(2), (1981), 231-239.

[19] McLeod, A.I., and Li, W.K.,Diagnostic checking ARMA time series models using squared residual autocorrelations, Journal of Time Series Analysis, 4, (1983), 269-273.

[20] Mo, B., Nie,H., Jiang, Y., Dynamic linkages among the gold market, US dollar and crude oil market, Physica A: Statistical Mechanics and its Applications, 491, (2018), 984-994.

[21] Narayan, P. K., Narayan, S., Zheng, X., Gold and oil futures markets: are markets efficient?, Applied Energy, 87(10), (2010), 3299-3303.

[22] Rodriquez, C., Measuring financial contagion: a copula approach, Journal of Empirical Finance, 14, (2007), 401-423.

[23] Sephton, P., Mann, J., Gold and crude oil prices after the great moderation, Energy Economics, 71, (2018), 273-281.

[24] Tse, K., Tsui, C., A Multivariate Generalized Autoregressive Conditional Heteroscedasticity Model with Time Varying Correlations, Journal of Business and Economic Statistics, 20(3), (2002), 351-362.

[25] Zhang, J., Wei, Y.-M., The crude oil market and the gold market: evidence for cointegration, causality and 
price discovery, Resource Policy, 35 (3), (2010), 168-177.

[26] Øglend, A., Lindbäck, E., Osmundsen, P., Shale gas boom affecting the relationship between LPG and oil prices, Energy J., 36 (4), (2015), 265-286.

[27] Wang, K.M., Lee, Y.M., Nguyen Thi, T.N., Does Gold Act as Inflation Hedge in the USA and Japan? , Transformations in Business \& Economics, 12, 2 (29), (2013), 20-43. 